Article

\title{
Study of the Application of Alkaline Extrusion to the Pretreatment of Eucalyptus Biomass as First Step in a Bioethanol Production Process
}

\author{
Aleta Duque *, Paloma Manzanares, Alberto González and Mercedes Ballesteros \\ Biofuels Unit, Energy Department-CIEMAT, Avda. Complutense, 40, 28040 Madrid, Spain; \\ p.manzanares@ciemat.es (P.M.); alb.gonzalez@ciemat.es (A.G.); m.ballesteros@ciemat.es (M.B.) \\ * Correspondence: aleta.duque@ciemat.es; Tel.: +34-91-346-6737
}

Received: 8 October 2018; Accepted: 23 October 2018; Published: 31 October 2018

check for updates

\begin{abstract}
Eucalyptus biomass was studied as a feedstock for sugars release using an alkaline extrusion plus a neutralization-based pretreatment. This approach would be a first step in a bioconversion process aimed at obtaining fuel bioethanol from eucalyptus biomass. The best operation conditions of extrusion (screw speed, temperature, liquid to solid ratio and $\mathrm{NaOH}$ amount) that lead to an effective destructuration of lignocellulose and enhanced sugar release were investigated. Two process configurations, with and without filtration inside the extruder, were tested. In the case without filtration, washed and not washed extrudates were compared. It was demonstrated that filtration step was convenient to remove inorganic salts resulting from neutralization and to promote the mechanical effect of extrusion, but limitations in the machine used in the work prevented testing of temperatures above $100{ }^{\circ} \mathrm{C}$ using this configuration. In the no filtration strategy, a temperature of $150^{\circ} \mathrm{C}$ allowed attaining the highest glucan and xylan conversion rates by enzymatic hydrolysis of extruded biomass, almost $40 \%$ and $75 \%$, respectively, of the maximum yield that could be attained if all carbohydrates contained in raw eucalyptus were converted to sugars. Some of the mechanisms and individual effects underlying alkaline extrusion of eucalyptus were figured out in this work, providing guidelines for a successful pretreatment design that needs to be further studied.
\end{abstract}

Keywords: lignocellulose; pretreatment; hardwood; extrusion; enzymatic digestibility; bioethanol

\section{Introduction}

Two of the biggest problems the world faces today are climate change and depletion of natural resources caused by increasing consumption of fossil fuels. In this context, renewable energies play a key role in relevant sectors as electricity, heat energy and transport by contributing to alleviate the harmful effects of such global tendency. Particularly for the transport sector, bioenergy in the form of liquid biofuels constitutes the major part (90\%) of the renewables energy contribution, which has been recently estimated at $3.1 \%$ by Renewable Energy Policy Network organization [1]. According to this report, $65 \%$ of liquid biofuels input is bioethanol, $29 \%$ is biodiesel and $6 \%$ is hydrobiodiesel, mainly derived from used vegetable oils and animal fats. Bioethanol is predominantly produced at global level from feedstocks that can also be consumed as human food such as sugar and starch, but concerns about the impact of biofuels on food security have focused the attention to advanced or second generation bioethanol produced from lignocellulosic type feedstocks to avoid food competition, continue renewable transport fuel supply and move towards a more sustainable scenario for biofuels production and use.

Among different lignocellulosic biomass sources, bioenergy crops and cropping systems are well positioned to produce second generation feedstocks provided that they are grown in land unsuitable 
for agriculture and show positive energy and carbon balances [2]. Tree species such as eucalyptus have received much attention in the last years due to several positive features such as capability of rapid growth in a wide range of climates and poor soils that make it a valuable candidate for bioenergy production.

Lignocellulosic biomass, such as eucalyptus wood, is composed of cellulose, a linear glucose polymer; hemicellulose, a heterogeneous polymer of pentoses and hexoses with certain amounts of uronic acids and acetyl substitutions; and lignin, a polymer of phenyl propane units that wraps the ensemble [3]. The amount of each component varies depending on the type of biomass, for instance, herbaceous biomass typically has $25-40 \%$ cellulose, $35-50 \%$ hemicellulose and $15-30 \%$ lignin. On the other hand, woods are composed of $40-55 \%$ cellulose, $24-40 \%$ hemicellulose and $18-35 \%$ lignin (softwood having higher lignin content than hardwood) [4]. Specifically, xylose is the most abundant sugar in hemicelluloses of grasses and hardwood, while mannose is the predominant component of softwood hemicellulose.

Lignocellulosic biomass is designed to resist degradation by ambient conditions or biological agents, which complicates the process of obtaining fermentable sugars to be converted to ethanol. However, by using a suitable method, lignocellulose can be altered and rendered more accessible to biological catalyst such as hydrolytic enzymes. Several pretreatment technologies have been proposed and studied [5,6], each having their own strengths and weaknesses. For instance, steam explosion has been proved to be an effective method to pretreat wood residues, especially hardwood type, since softwoods are more recalcitrant and typically require higher pretreatment severity and possibly the addition of an acid catalyst [7]. Several references can be found in the literature about eucalyptus pretreatment for sugar release. For example, very high cellulose recovery and enzymatic hydrolysis yield were obtained by pretreating Eucalyptus globulus at $195^{\circ} \mathrm{C}$ for 6 min [8]. Furthermore, dilute acid pretreatment aided by microwave cooking of eucalyptus wood chips resulted in maximum glucose hydrolysis yield of $74 \%$ of theoretical, although severe conditions that involved some xylose degradation were used [9]. After testing several methods and conditions for the pretreatment of eucalyptus bark, including hot water extraction, acid pretreatment, alkali pretreatment and a combination of both, Lima et al. [10] reported that autoclaving of this biomass with $\mathrm{NaOH} 4 \%$ at 1.05 bar for $1 \mathrm{~h}$ gave the best results in terms of glucose release (59-65\%). This result indicates that the use of an alkaline catalyst is a possibility worth exploring.

On the other hand, extrusion has been reported as a versatile pretreatment with promising features [7] that single it out as an interesting option for treating eucalyptus to obtain enhanced enzymatic digestibility while avoiding sugar degradation. Although preferred for the treatment of herbaceous biomasses, some woody type materials have also been successfully processed by extrusion. For instance, pine wood chips were pretreated in a single-screw extruder at optimal conditions of $180{ }^{\circ} \mathrm{C}, 150 \mathrm{rpm}$ and $25 \%$ moisture, obtaining sugar recoveries over $65 \%$ [11]. Nevertheless, Lee et al. [12] alleged a limited effect of mechanical kneading with addition of only water for the fibrillation of Douglas fir, and so they proposed an extrusion in a twin-screw extruder aided by ethylene glycol [13], or a combination of hot-compressed water followed by extrusion [14]. The latter combination was tested by the authors also for eucalyptus, resulting in a glucose release yield over $30 \%$ (of original wood weight) and xylose release around $4 \%$. The addition of chemicals to the extrusion process has been reported in several papers. Extrusion of poplar sawdust under acidic conditions ( $4 \%$ wt. $\mathrm{H}_{2} \mathrm{SO}_{4}$ ) and high temperature of $185^{\circ} \mathrm{C}$ resulted in saccharification yields of cellulose over $65 \%$ [15]. Moreover, Senturk-Ozer et al. [16] proved that a good flowability of hard-wood type biomass could be achieved inside a twin-screw extruder within a context of alkaline pretreatment. Alkaline extrusion was used to pretreat Eucalyptus Forest Residues, among other biomasses, in a configuration that included the alkaline pretreatment, followed by neutralization with $\mathrm{H}_{3} \mathrm{PO}_{4}$, filtration and addition of hydrolytic enzymes inside the extruder [17]. In that work, the amount of $\mathrm{NaOH}$ employed was $8 \%$ and the temperature and screw speed were set to $75^{\circ} \mathrm{C}$ and $200 \mathrm{rpm}$, respectively. The saccharification 
yield of cellulose obtained was $14 \mathrm{~g} / 100 \mathrm{~g}$ raw material. However, only one set of conditions were tested and thus, limited conclusions can be drawn about extrusion performance on eucalyptus biomass.

One of the difficulties of working with extrusion is the complex inter-relations among the operation variables [7]. In this exploratory work about extrusion of eucalyptus, the effect of the screw speed, the temperature, the liquid to solid (L/S) ratio and the proportion of $\mathrm{NaOH}$ to dry biomass $(\mathrm{NaOH} / \mathrm{DM})$ were investigated separately to better understand their individual effects on the mechanical energy requirements of the pretreatment (Specific Mechanical Energy, SME), composition of the extrudates and their enzymatic digestibility when submitted to incubation with hydrolytic enzymes. This approach was tested in an extrusion process strategy that includes a filtration step to remove part of the liquid added into the extruder, that the authors had previously tested on other biomasses [18]. Moreover, an extrusion strategy without filtration and a process scheme where the pretreated material is washed with water outside the extruder were also studied aimed at testing the effect of extrusion process strategy for sugar release by enzymatic hydrolysis of extrudates.

\section{Materials and Methods}

\subsection{Raw Material}

Eucalyptus grandis, de-barked trunk portion of diameter between 190 and $60 \mathrm{~mm}$, was provided by the National Institute of Agricultural Research (INIA, Uruguay). Eucalyptus trees were harvested during October and November, 2017, from two different stands located in the Department of Rivera (Uruguay). They were cut into logs, debarked on site, and moved to the research station where they were stored for two months to be air-dried. Afterwards, logs diameter was measured with tree calipers and portions between 60 and $190 \mathrm{~mm}$ in diameter were selected as feedstock for this work. Logs were chipped and stored again until moist was around $20 \%$. Finally, chips were milled to $2 \mathrm{~mm}$ and kept until use (11.9\% moisture).

The composition of eucalyptus biomass was close to $60 \%$ carbohydrates ( $46.9 \%$ cellulose, $12.9 \%$ hemicellulose), $31.1 \%$ lignin and $<1 \%$ ash (see Section 2.3 ).

\subsection{Extrusion Pretreatment}

Eucalyptus biomass was pretreated by alkaline extrusion in a co-rotating twin-screw extruder (Clextral Processing Platform Evolum ${ }^{\circledR} 25$ A110, Clextral, Firminy, France) with 6 barrels and length to diameter ratio (L/D) equal to 24 . The configuration used was one conceived for the alkaline extrusion with filtration inside the extruder, adapted from [18]. In this configuration, the alkaline solution (diluted $\mathrm{NaOH}$ ) is introduced in barrel \#2, the acid solution entered in barrel \#4 and barrel \#5 is a filter to separate the liquid and solid after neutralization. The exact screw configuration used for the present work is presented in Figure 1 and discussed in detail later in Section 3.1.

A first control sample was run with addition of water instead of chemical catalyst to assess the mechanichal-thermal and chemical effects separately. Afterwards, the influence of four operation variables: Screw speed (SS), temperature (T), L/S ratio in the reaction zone and $\mathrm{NaOH} / \mathrm{DM}$, in the pretreatment performance was tested. Table 1 shows the different experiments carried out to determine the singular effect of each of the variables. The objective was to vary one of the variables while keeping the rest of the variables constant. All deviations from this principle were directed towards the achievement of a regular flow inside the extruder and the adjustment of the parameters was made upon observation of the course of extrusion experiments. 


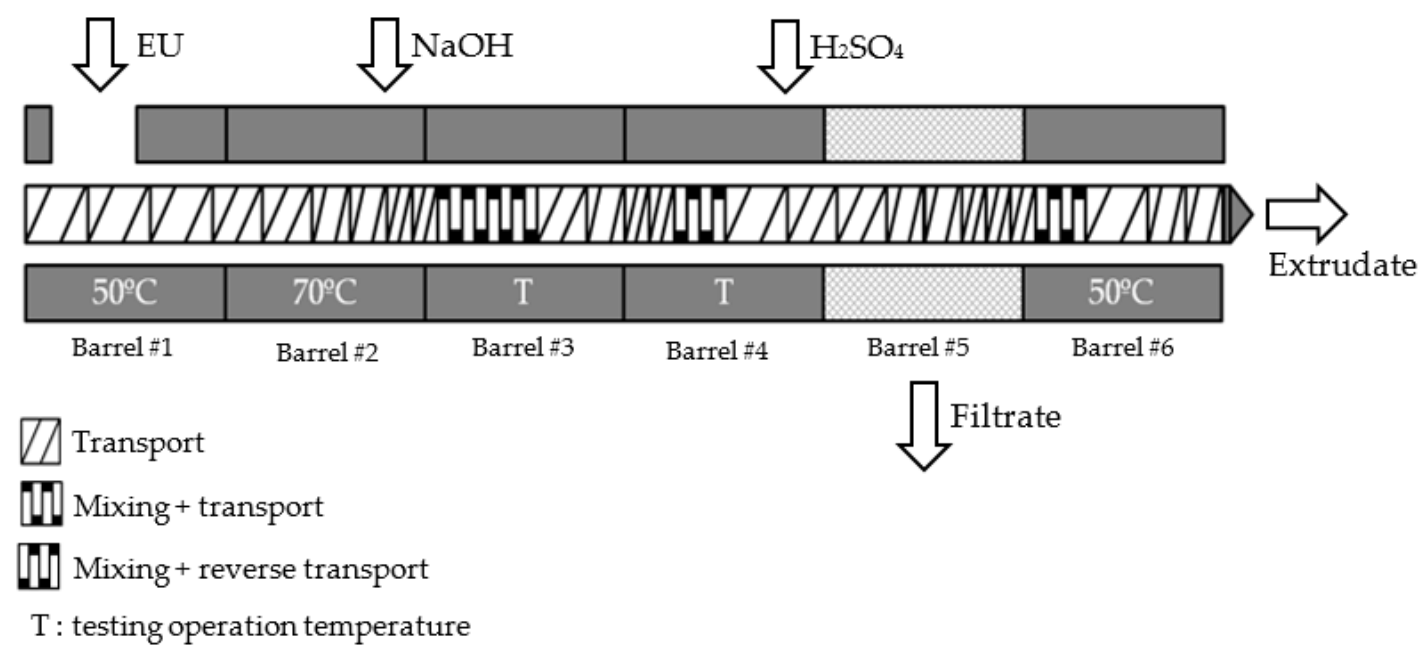

Figure 1. Barrel and screw configuration for the alkaline extrusion of eucalyptus with neutralization and filtration in a twin-screw extruder.

Table 1. List of extrusion experiments carried out, values of operation variables and information about the processing of the samples.

\begin{tabular}{|c|c|c|c|c|c|c|c|}
\hline Experiment & Assays & $\mathrm{R}(\% w / w)$ & L/S $(w / w)$ & $\mathrm{T}\left({ }^{\circ} \mathrm{C}\right)$ & SS (rpm) & Filter & Washed \\
\hline $\mathrm{W}$ & Control & - & 1.2 & 75 & 200 & Yes & No \\
\hline \multirow{3}{*}{ SS } & 1 & 8.5 & 1.2 & 75 & 100 & Yes & No \\
\hline & 2 & 8.5 & 1.2 & 75 & 200 & Yes & No \\
\hline & 3 & 8.5 & 1.2 & 75 & 300 & Yes & No \\
\hline \multirow{2}{*}{$\mathrm{T}$} & 4 & 8.5 & 1.2 & 100 & 200 & Yes & No \\
\hline & 5 & 8.5 & 1.2 & 125 & 200 & [1] & [1] \\
\hline \multirow{2}{*}{$\mathrm{L} / \mathrm{S}$} & 6 & 8.5 & 0.6 & 75 & 200 & Yes & No \\
\hline & 7 & 8.5 & 1.5 & 75 & 200 & Yes & No \\
\hline \multirow{3}{*}{$\mathrm{NaOH}$} & 8 & 5 & 0.7 & 100 & 150 & Yes & No \\
\hline & 9 & 10 & 1.2 & 100 & 150 & Yes & No \\
\hline & 10 & 20 & 1.2 & 100 & 250 & Yes & No \\
\hline \multirow{2}{*}{ NF } & 11 & 8.5 & 1.2 & 125 & 300 & No & No \\
\hline & 12 & 8.5 & 1.2 & 150 & 300 & No & No \\
\hline \multirow{2}{*}{ NFW } & 13 & 8.5 & 1.2 & 125 & 300 & No & Yes \\
\hline & 14 & 8.5 & 1.2 & 150 & 300 & No & Yes \\
\hline
\end{tabular}

W—extrusion with water; SS—-screw speed; T—-temperature; L/S—liquid to solid ratio; $\mathrm{NaOH}$-amount of alkali; NF-without filtration; NFW—washing of extrudates without filtration; [1] Failed run.

In another set of experiments the process configuration was changed due to the pretreatment needs, as it will be explained later in Section 3.4.1.

\subsection{Materials Characterization}

Untreated eucalyptus and pretreated materials (extrudates) were analyzed according to the National Renewable Energy Laboratory (NREL, Golden, CO, USA) laboratory analytical procedures (LAP) for biomass analysis [19].

\subsection{Evaluation of the Enzymatic Digestibility}

Enzymatic hydrolysis of untreated and alkaline extruded eucalyptus was carried out by triplicate in Erlenmeyer flasks at $5 \% w / w$ solids load with a total volume of $50 \mathrm{~mL} .15 \mathrm{FPU} / \mathrm{g}$ dry matter of a commercial cellulolytic cocktail Cellic ${ }^{\circledR} \mathrm{CTec} 2$, kindly provided by Novozymes A/S (Copenhagen, 
Denmark), were added to each flask. The hydrolysis tests were done in citrate buffer $50 \mathrm{mM}, \mathrm{pH} 4.8$, and with the addition of $1 \% v / v$ of sodium azide. The Erlenmeyer flasks were agitated in an orbital shaker at $50{ }^{\circ} \mathrm{C}$ and $150 \mathrm{rpm}$ for $72 \mathrm{~h}$. Samples were taken each $24 \mathrm{~h}$ and glucose and xylose were analyzed by HPLC as explained below.

The sugar release yield was calculated as the amount of glucose (GR) or xylose (XR) measured in the hydrolysis media divided per $100 \mathrm{~g}$ of dry extrudate. Alternatively, glucan and xylan conversions (GC and $\mathrm{XC}$ ) values were obtained by dividing the corresponding sugar release by the glucose or xylose content of the extrudate and expressed as percentage.

\subsection{Analytical Methods}

Monomeric sugars were analyzed by high-performance liquid chromatography (HPLC) in a Waters 2695 liquid chromatograph with refractive index detector. A CARBOSep CHO-782 LEAD column (Transgenomic, Omaha, NE, USA) was used, operating at $70{ }^{\circ} \mathrm{C}$ with Milli-Q water (Millipore) as mobile-phase $(0.5 \mathrm{~mL} / \mathrm{min})$.

Acetic acid was analyzed by HPLC in a Waters 2414 liquid chromatograph with refractive index detector. An ionic exclusion column Aminex HPX-87H (BioRAd Labs, Hercules, CA, USA) was operated at $65^{\circ} \mathrm{C}$ with sulphuric acid $0.05 \mathrm{M}$ as mobile-phase $(0.6 \mathrm{~mL} / \mathrm{min})$.

Furfural and HMF in the filtrates were analyzed by HPLC (Hewlett Packard, Palo Alto, CA, USA), using an Aminex ion exclusion HPX-87H cation-exchange column (Bio-Rad Labs, Hercules, CA, USA) at $65{ }^{\circ} \mathrm{C}$. Mobile phase was $89 \% 5 \mathrm{mM} \mathrm{H}_{2} \mathrm{SO}_{4}$ and $11 \%$ acetonitrile at a flow rate of $0.7 \mathrm{~mL} / \mathrm{min}$. Column eluent was detected with a 1040A Photodiode-Array detector (Agilent, Waldbronn, Germany).

\section{Results and Discussion}

\subsection{Screw Configuration}

One of the features that make extrusion such a versatile pretreatment is the possibility to change the screw elements that, arranged one after another, constitute the screw configuration. These elements have different shapes and effects on the biomass and the way they are placed helps creating and separating different zones along the extrusion machine. The screw configuration has not only a big influence on the severity of the pretreatment, but it also determines in first instance the flow inside the extruder, this is, the feasibility or not of the pretreatment. Thus, the first approach to the extrusion of a new biomass is to study a configuration in which it can be operated.

The screw configuration was designed to be divided into several zones to perform the alkaline extrusion, neutralization and filtration of the biomass all inside the extruder (Figure 1). The first zone was dedicated to the feeding, where conveying screws were used, and it comprised barrels \#1 and \#2. $\mathrm{NaOH}$ solution entered at the end of barrel \#2 and it was mixed with the eucalyptus biomass and heated along barrels \#3 and part of \#4; this was the reaction zone, terminated with a reverse kneading block. The acid solution was pumped at the end of barrel \#4 and the neutralization plus filtration took place in barrel \#5. After the reverse kneading block placed at the beginning of barrel \#6, the discharge zone started. The proposed configuration is based in a similar one reported by Duque et al. [18] for the extrusion of barley straw. In that screw profile, reverse flow screws were placed instead of reverse kneading blocks. The exact configuration was tested in a first trail with eucalyptus with no success. The different characteristics of eucalyptus with respect to barley straw (more hardness and lower water retention) caused blockage of the reverse screws, leading to full stop of the machine. To soften the screw profile, while maintaining the neutralization and filtration zone separated inside the extruder, the reverse flow screws were replaced by the above-mentioned reverse kneading blocks as depicted in Figure 1.

Many authors have established the importance of constraint elements in extrusion for the fibrillation of lignocellulosic biomass and improvement of the enzymatic digestibility [16,20-22]. Furthermore, Vandenbossche et al. [23] observed that insufficient backpressure caused unstable flow 
inside the extruder and prevented a good filtration of dehydrated sweet corn co-products treated inside the machine, first with $\mathrm{NaOH}$ and then neutralized with $\mathrm{H}_{3} \mathrm{PO}_{4}$. Following the same pretreatment concept of alkaline extrusion plus neutralization and filtration, Brault [17] had to adapt the screw profile used for the pretreatment of sweet corn co-products to the extrusion of Eucalyptus residues, by placing an additional reverse flow element in the reaction zone to increase destructuration and by removing one constraint element after the filter to ensure the formation of a stable dynamic plug.

Therefore, the configuration for the extrusion of eucalyptus in the present paper was designed to provide high shearing and mixing, while keeping a continuous flow and four separated zones with different temperatures: Feeding, reaction zone, neutralization and filtration zone, and discharge.

\subsection{Extrusion with Water}

A control run was carried out by pumping water instead of alkali and acid solutions to determine the effect of extrusion alone on eucalyptus biomass. Some authors have emphasized the importance of adding a rheological modifier to help the flow inside the extruder [16,24-26]. In agreement with this idea, Lamsal et al. [25] reported problems in the extrusion of soybean hulls at low moisture $(<35 \%)$ in a twin-screw extruder. In the present work, flow constraints were also observed during the extrusion trial with water, but a representative sample could be obtained to be used as a control for the study. The difficulty in the flow is revealed by the SME value, presented in Figure 2, which is the highest of all the extrusion trials. In alkaline extrusion, $\mathrm{NaOH}$ acts as a flux modifier for the biomass suspension, increasing the viscosity and reducing the shear strength, in comparison to extrusion with only water, which requires a higher energy input.

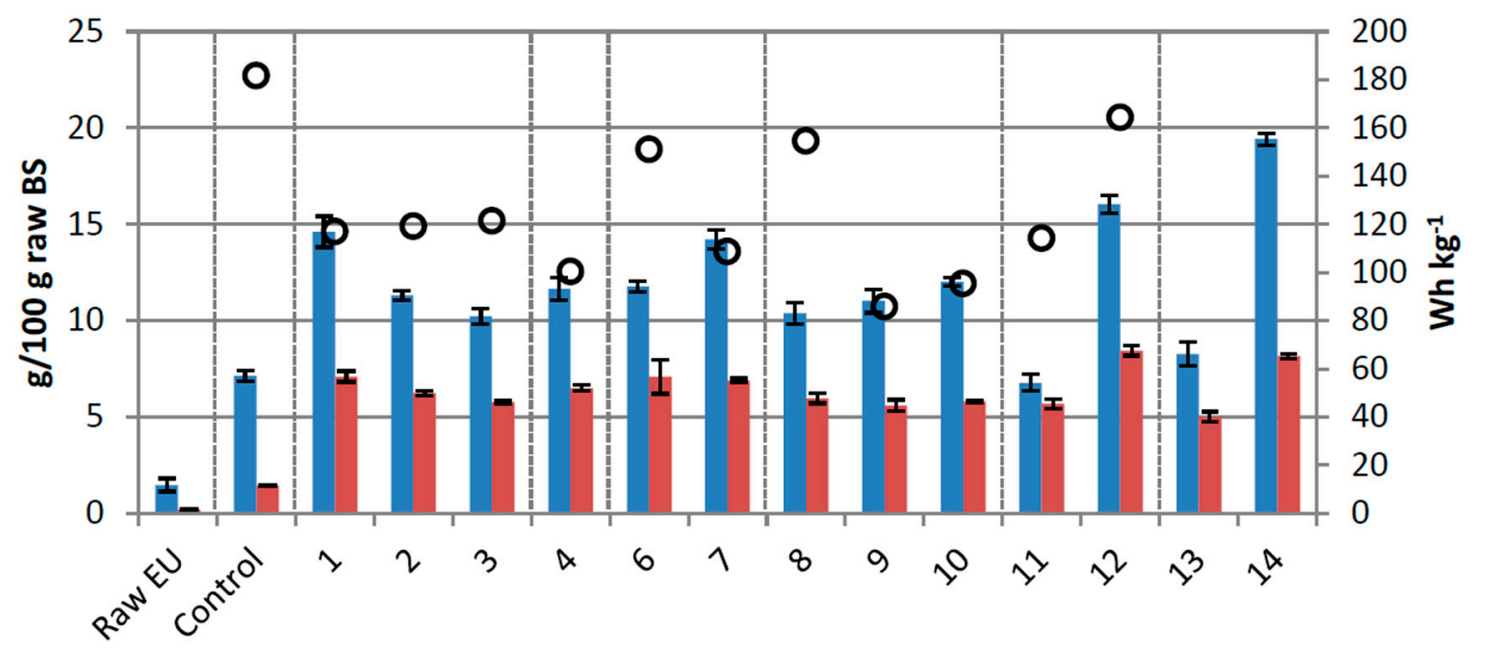

$\square \mathrm{GR} \square \mathrm{XR}$ OSME

Figure 2. Glucose (GR) and xylose (XR) release (in g per $100 \mathrm{~g}$ ) of raw biomass and eucalyptus extruded with water (control) and with $\mathrm{NaOH}$ at varying screw speed, temperature, liquid to solid ratio and catalyst ratio (experiments 1 to 10). Specifical mechanical energy (SME) of each experiment (in $\mathrm{Wh} \mathrm{kg}^{-1}$ ). Experiment \#1, 2 \& 3-study of SS; Experiment \#2 \& 4-study of T; Experiment \#2, 6 \& 7-study of L/S; Experiment \#8, 9 \& 10-study of NaOH/DM; Experiment \#11 \& 12-without filtration; Experiment \#13 \& 14-washing of extrudates without filtration.

The control sample extruded with water was submitted to EH to check the effect of the mechanical-thermal effects of extrusion (excluding the chemical pretreatment) on the enzymatic digestibility of eucalyptus and the results can be seen in the third and fourth columns of Figure 2 . Glucose and xylose release (GR and XR) from control extrudate are 7.1 and $1.5 \mathrm{~g} / 100 \mathrm{~g}$ extrudate, respectively, which means 5 - and 7-fold times more glucose and xylose produced than by hydrolysis of the untreated eucalyptus. Nevertheless, the glucan and xylan conversions were still under $15 \%$ of 
theoretical levels. These low yields were highly improved by the combination of alkaline pretreatment with extrusion in the next trials, particularly in the case of xylan, as will be discussed later.

Control extrudate composition was not significantly affected with respect to the raw material (Table 2, rows 1 and 2). In absence of a chemical catalyst, and at the mild temperature tested $\left(75^{\circ} \mathrm{C}\right)$, there was no sugar solubilization or degradation. This is confirmed by the composition of the filtrate reported in Table 3, where only traces $(<0.1 \%)$ of glucose, xylose and acetic acid were found in control sample, indicating again the low effect of the water-based pretreatment on lignocellulose fractionation. Moreover, eucalyptus is a biomass with a very low content of ash $(<1 \%)$ and extractives $(2.4 \%$, data not shown), so there is not a concentration effect from the partial solubilization of those compounds, as was the case for barley straw [27]. The efficiency of the filtration, defined as the weight of filtrate in the total output weight (filtrate and extrudate), compiled in Table 3, was only 19\%, which is a result of the bad flowability of the mixture, so contributing to a low sugar extraction.

Table 2. Main components (in $\mathrm{dwb}$ ) of raw eucalyptus and extrudates, with standard deviation.

\begin{tabular}{ccccc}
\hline Experiment & Cellulose (\%) & Hemicellulose (\%) & Lignin (\%) & Ash (\%) \\
\hline Raw EU & $46.90 \pm 1.21^{\mathrm{a}}$ & $12.87 \pm 0.35^{\mathrm{a}, \mathrm{b}, \mathrm{c}, \mathrm{d}}$ & $31.15 \pm 0.40^{\mathrm{a}, \mathrm{b}}$ & $0.86^{\mathrm{a}} \pm 0.00^{\mathrm{a}}$ \\
Control & $44.90 \pm 1.86^{\mathrm{a}, \mathrm{b}, \mathrm{c}}$ & $13.71 \pm 0.32^{\mathrm{a}, \mathrm{c}, \mathrm{d}, \mathrm{e}}$ & $32.97 \pm 0.86^{\mathrm{c}, \mathrm{d}}$ & $0.57^{\mathrm{a}} \pm 0.05^{\mathrm{a}}$ \\
1 & $42.56 \pm 3.51^{\mathrm{b}, \mathrm{c}}$ & $12.13 \pm 0.94^{\mathrm{a}, \mathrm{b}, \mathrm{c}}$ & $32.03 \pm 1.00^{\mathrm{a}, \mathrm{c}}$ & $3.78 \pm 0.37^{\mathrm{b}}$ \\
2 & $42.56 \pm 1.19^{\mathrm{b}, \mathrm{c}}$ & $11.76 \pm 1.51^{\mathrm{a}, \mathrm{b}}$ & $31.22 \pm 0.41^{\mathrm{a}, \mathrm{b}}$ & $7.35 \pm 0.15^{\mathrm{c}}$ \\
3 & $41.79 \pm 0.88^{\mathrm{c}}$ & $12.16^{\mathrm{a}} \pm 0.20^{\mathrm{a}, \mathrm{b}, \mathrm{c}}$ & $28.86 \pm 0.10^{\mathrm{e}}$ & $9.28 \pm 0.01^{\mathrm{d}}$ \\
4 & $43.14 \pm 1.54^{\mathrm{a}, \mathrm{b}}$ & $11.47 \pm 0.68^{\mathrm{d}, \mathrm{e}}$ & $29.67 \pm 0.65^{\mathrm{f}}$ & $7.01 \pm 0.10^{\mathrm{c}}$ \\
6 & $41.71 \pm 0.56^{\mathrm{b}, \mathrm{c}}$ & $12.04 \pm 0.43^{\mathrm{c}, \mathrm{d}, \mathrm{e}}$ & $30.43 \pm 0.67^{\mathrm{d}}$ & $7.37 \pm 0.06^{\mathrm{e}}$ \\
7 & $46.97 \pm 1.21^{\mathrm{a}}$ & $15.59 \pm 2.61^{\mathrm{e}}$ & $31.21 \pm 0.31^{\mathrm{a}, \mathrm{b}}$ & $5.65 \pm 0.10^{\mathrm{f}}$ \\
8 & $45.66 \pm 0.10^{\mathrm{a}, \mathrm{b}}$ & $14.95 \pm 1.70^{\mathrm{d}, \mathrm{e}}$ & $32.90 \pm 0.61^{\mathrm{c}, \mathrm{d}}$ & $4.16^{\mathrm{a}} \pm 0.07^{\mathrm{g}}$ \\
9 & $45.48 \pm 0.82^{\mathrm{a}, \mathrm{b}, \mathrm{c}}$ & $11.36 \pm 0.21^{\mathrm{a}, \mathrm{b}}$ & $31.70 \pm 0.18^{\mathrm{a}}$ & $5.22 \pm 0.03^{\mathrm{h}}$ \\
10 & $44.60 \pm 1.77^{\mathrm{a}, \mathrm{b}, \mathrm{c}}$ & $11.02 \pm 1.26^{\mathrm{b}}$ & $30.32 \pm 0.22^{\mathrm{b}, \mathrm{f}}$ & $11.17 \pm 0.08^{\mathrm{i}}$ \\
11 & $39.23 \pm 2.31^{\mathrm{a}, \mathrm{b}, \mathrm{c}}$ & $11.78 \pm 0.47^{\mathrm{a}, \mathrm{b}}$ & $27.69 \pm 0.45^{\mathrm{g}}$ & $14.91 \pm 0.12^{\mathrm{j}}$ \\
13 & $38.76 \pm 0.36^{\mathrm{b}, \mathrm{c}}$ & $11.24 \pm 0.16^{\mathrm{b}}$ & $27.99 \pm 0.22^{\mathrm{g}}$ & $14.54 \pm 0.10^{\mathrm{j}}$ \\
14 & $50.05 \pm 0.38^{\mathrm{d}}$ & $12.72 \pm 0.13^{\mathrm{a}, \mathrm{b}, \mathrm{c}}$ & $32.60 \pm 0.15^{\mathrm{e}, \mathrm{f}}$ & $2.04 \pm 0.02^{\mathrm{k}}$ \\
\hline
\end{tabular}

Values followed by the same letters are not significantly different at $p=0.05$.

Table 3. Filtration parameters and sugar and acetyl groups recovery yields in the filtrates and washing liquid of the different extrusion experiments.

\begin{tabular}{cccccc}
\hline Experiment & $\begin{array}{c}\text { Filtration } \\
\text { Efficiency }\end{array}$ & L/S Filtration & Total Glucose & Total Xylose & Acetic Acid \\
\hline & $\begin{array}{c}\text { g Filtrate/100 } \\
\text { Total Output }\end{array}$ & & $\begin{array}{c}\text { \% of Gluc in } \\
\text { Raw EU }\end{array}$ & $\begin{array}{c}\text { \% of xyl in } \\
\text { Raw EU }\end{array}$ & $\begin{array}{c}\text { \% of ac Acid in } \\
\text { Raw EU }\end{array}$ \\
\hline Control & 19.0 & 3.9 & 0.0 & 0.3 & 0.8 \\
1 & 69.6 & 3.9 & 0.4 & 8.0 & 27.3 \\
2 & 55.1 & 3.9 & 0.1 & 5.9 & 30.8 \\
3 & 58.2 & 3.9 & 0.1 & 5.6 & 27.3 \\
4 & 59.2 & 3.9 & 0.2 & 8.0 & 24.0 \\
6 & 48.3 & 3.4 & 0.2 & 5.3 & 36.0 \\
7 & 50.8 & 4.2 & 0.3 & 6.9 & 36.5 \\
8 & 43.0 & 4.9 & 0.3 & 2.0 & 64.5 \\
9 & 68.8 & 5.0 & 0.4 & 11.1 & 58.5 \\
10 & 64.6 & 0.0 & 2.2 & 42.6 \\
13 & Washing liquid & 0.1 & 3.2 & 33.4 \\
\hline
\end{tabular}


Thus, there is a certain contribution of extrusion alone to the destructuration of eucalyptus biomass structure, resulting in a small increase of GC value, but a chemical catalyst (in the present study, $\mathrm{NaOH}$ ) is proposed to further open the fiber and boost the enzymatic digestibility.

\subsection{Alkaline Extrusion with Filtration}

\subsubsection{Effect of Screw Speed}

The screw speed is a parameter with a complex influence on the performance of the pretreatment. On the one hand, it is inversely proportional to the duration of the pretreatment; the higher the screw speed, the shorter the residence time inside the extruder. On the other hand, higher motor speeds correspond to higher torque values [7].

In the present work, three SS were tested: 100, 200 and $300 \mathrm{rpm}$. The results depicted in Figure 2 (columns 1, 2 and 3), show that lower screw speeds favor the release of sugars by EH. Specifically, at $100 \mathrm{rpm}, 14.6 \mathrm{~g}$ glucose and $7.1 \mathrm{~g}$ of xylose per $100 \mathrm{~g}$ extrudate were released after $72 \mathrm{~h}$ of incubation with enzymes (which is $29.6 \%$ and $55.1 \%$ of theoretical glucan and xylan, respectively). These values are in agreement with the ones reported by Brault [17], working in a similar configuration. A statistical analysis following the ANOVA methodology confirmed that the differences in the enzymatic digestibility of the extrudates between the lower and the highest SS values were significant $(p \leq 0.05)$.

The screw speed had also a remarkable effect on the performance of the filtration barrel. At $100 \mathrm{rpm}$, the filtration efficiency is much higher than at 200 or $300 \mathrm{rpm}$, as can be seen in Table 3 . However, the amount of sugars solubilized is very similar in all three conditions and negligible in the case of glucose. The xylose found in the filtrates is $\leq 8 \%$ of the xylose contained in the raw material, which means about $1 \%$ of the weight of the dry eucalyptus. In spite of the low amount of sugars solubilized in the filtrate, the filtration step is necessary, since there is a significant amount of liquid coming from the neutralization inside the extruder that needs to be removed before processing the material.

The fact that the EH works better with a material extruded at low screw speed shown in the present work is in contrast with the results of Karunanithy et al. [11], who obtained a better digestibility of extruded pine wood chips, as the screw speed increased from 100 to $200 \mathrm{rpm}$. The authors attribute this improvement of the EH yield to the higher energy exerted at higher SS, which would result in shortening of the fibers. However, they also pointed out that the shear forces responsible for this fiber length reduction are relatively low in the single-extrusion process that they used, compared to the intermeshing co-rotating twin-screw extrusion, as the one employed in the present work. This means that higher speeds could be needed in a single-screw extrusion to reach the level of shear displayed at $100 \mathrm{rpm}$ in the twin-screw extrusion. Zhang et al. [28] extruded corn stover with water in a twin-screw extruder at speeds ranging from 40 to $140 \mathrm{rpm}$, and the SS was found to have a significant effect on the release of glucose by EH, increasing the yields as the speed increased up to $80 \mathrm{rpm}$ and beyond that point having a negative effect. Similar trends were observed by Yoo et al. [24] on soybean hulls and Karunanithy et al. [29] on switchgrass, although the optimum SS were different, 350 and $100 \mathrm{rpm}$, respectively. Interestingly, the prairie cord grass extruded by Karunanithy et al. [29] showed a similar behavior to the one of eucalyptus in the present work, and the glucose yield increased as the SS decreased. The effect of SS (70 and $150 \mathrm{rpm}$ ) on the EH yield of alkali-extruded olive tree pruning was not significant according to the work of Negro et al. [30]. The biomass used, the type of extruder and the presence or not of a catalyst seem to have a certain influence on the effect of the screw speed, therefore, the results have to be interpreted within the conditions at which the experiments are carried out. In the case of eucalyptus, a hardwood, lower speed seems to be necessary to reinforce the destructuration of the fibers. 


\subsubsection{Effect of Temperature}

Temperature is not constant along the barrels of the extruder; instead, a temperature profile is set to accompany the material flow through the different zones. The key elements in this work were barrels \#3 and 4 (Figure 1), where the alkaline reaction took place. The temperature profile beyond those barrels was set aiming at achieving a proper flow inside the machine. The effect of temperature of the reaction zone on the extrusion performance was evaluated at 75,100 and $125^{\circ} \mathrm{C}$. At the highest temperature backflow problems appeared, making it impossible to get a representative sample from trial \#5. These problems can be attributed to the high temperature reached at the filtration barrel. Due to the limited length of the twin-screw extruder used in the present work, the temperature in barrel $\# 5$ is close to $100{ }^{\circ} \mathrm{C}$, causing evaporation and affecting the formation of a dynamic plug necessary for the correct running of the machine [23].

Comparing the results from extrusion at $75{ }^{\circ} \mathrm{C}$ and $100{ }^{\circ} \mathrm{C}$ (trials \#2 and \#4) shown in Figure 2 and Table 2, there are no significant differences in terms of enzymatic digestibility or composition between both samples. Both filtrates are also comparable, as can be concluded from data in Table 3 . The glucose and xylose release at these values were close to 11.5 and $6.5 \mathrm{~g} / 100 \mathrm{~g}$ extrudate, respectively, corresponding to $23 \%$ and $43 \%$ of hydrolysis of the potential glucan and xylan of the extrudate. In addition, it was observed that the energy input required for the extrusion at $100{ }^{\circ} \mathrm{C}$ (trial \#4) was lower than the one at $75{ }^{\circ} \mathrm{C}$ (trial \#2), which is due to the thermal softening of the eucalyptus and subsequent decrease of the viscosity of the biomass suspension [31].

The somehow contradictory effects of temperature on extrusion depending on the type of biomass and configuration of the pretreatment have been discussed elsewhere [7]. In general, there is a positive effect of the increase of temperature on the enzymatic digestibility of extrudates [11], but in some cases a threshold is reached, beyond which the further increase of temperature is detrimental $[27,29,32]$. The interval of temperature tested in this work seems to be too narrow to see any effect of this variable on any of the studied categories. A woody biomass as eucalyptus may need higher temperatures to effectively disrupt the lignocellulosic matrix. In the scientific literature, pine wood chips were successfully extruded at temperatures as high as $180^{\circ} \mathrm{C}$ [11]. Douglas fir and eucalyptus previously pretreated by autohydrolysis were submitted to extrusion at 170 and $180{ }^{\circ} \mathrm{C}$, respectively [14]. Furthermore, acid extrusion of poplar sawdust was carried out at $185^{\circ} \mathrm{C}$ [15], while extrusion of hardwood with the help of flux modifiers (CMC, black liquor) was possible at temperatures up to $120^{\circ} \mathrm{C}$ [16]. Thus, temperature above $100{ }^{\circ} \mathrm{C}$ seems to be a constant for the extrusion (alone or with a chemical catalyst) of woody biomass. The increase of temperature could not be addressed with this first process configuration, so it was contemplated in a next set of trials (see Section 3.4).

\subsubsection{Effect of L/S Ratio in the Reaction Zone}

As the biomass moves forward inside the extruder, and the liquids (in this case, alkaline and acidic solutions) are pumped into it, the proportion between liquid and solid varies in the proposed working configuration (Figure 1). The L/S ratio in the reaction zone (barrels \#3 and 4) is the most important for the pretreatment, since it influences the rate of shear developed during the alkaline contact time. Meanwhile, the L/S ratio in the neutralization zone affects the performance of the filtration, and consequently, the effectiveness of the separation and extraction of soluble compounds in the liquid fraction, and hence, the solids content in the extrudate.

For the purpose of this work, the L/S ratio studied is the one in the reaction zone. Since it is a variable closely related to the amount of catalyst added, to keep the $\mathrm{NaOH} / \mathrm{DM}$ constant, while testing different $\mathrm{L} / \mathrm{S}$ ratios, the concentration of the alkaline solution was varied accordingly. The values tested were 0.6, 1.2 and 1.5, corresponding to trials \#6, 2 and 7.

Looking at the results presented in Figure 2, the increase in the L/S ratio seems to have a positive effect on the release of glucose by EH. This is confirmed by the statistical analysis of the data, which found significant differences between trials \#2 and 6 and trial \#7. Nevertheless, no significant effect was observed for xylose release. The maximum GR was, then, $14.2 \mathrm{~g} / 100 \mathrm{~g}$ extrudate, equivalent to 
$27.5 \%$ of glucan conversion, and was obtained with the extrudate produced with $1.5 \mathrm{~L} / \mathrm{S}$ (experiment \#7). At this condition, the XR was close to $7 \mathrm{~g} / 100 \mathrm{~g}$ extrudate ( $44 \%$ xylan conversion). The increase of GR found at the highest $\mathrm{L} / \mathrm{S}$ ratio tested could be related to the better impregnation of the eucalyptus with the $\mathrm{NaOH}$ solution when the amount of liquid is high. Silva et al. [32] also obtained better results at high $\mathrm{L} / \mathrm{S}$ ratios for the extrusion of sugarcane bagasse with an ionic liquid.

At the same time, the recorded SME values clearly decrease as the L/S ratio increases from 0.6 to 1.2 and 1.5. Low amounts of liquids have been correlated to higher friction forces, thus explaining the high energy input necessary at $0.6 \mathrm{~L} / \mathrm{S}[16,24]$.

Concerning the extrudate composition shown in Table 2, the effect of the increase of the L/S ratio reflects on a certain increase of the glucose and xylose content of the extrudate \#7 compared to \#2 and 6. Moreover, the filtration efficiency (see Table 3) was lower when L/S was 0.6 (experiment \#6) with respect to 1.2 (experiment \#2). This can be due to a lower amount of liquid which would imply lower filtration flow in the case of trial \#6. The amount of sugars recovered in the filtrate is in any case the same. Supporting these findings, Choi et al. [33] found that the glucan content in the extrudate increased and the lignin content decreased as the L/S ratio increased from 4 to 8 for the alkaline pretreatment of empty fruit bunches, especially at high $\mathrm{NaOH}$ loadings $(>5 \% \mathrm{NaOH} / \mathrm{DM})$.

Flow considerations aside, the results indicate that the L/S parameter should be kept as high as possible to obtain the better glucan digestibility, which would result as well in a lower energy consumption of the machine.

\subsubsection{Effect of $\mathrm{NaOH} / \mathrm{DM}$ Ratio}

Three $\mathrm{NaOH} / \mathrm{DM}$ ratios were tested: $5 \%, 10 \%$ and $20 \%$. Taking into account the previous results, the evaluation of the amount of catalyst was made at $100{ }^{\circ} \mathrm{C}$, the highest temperature that allows the operation of the machine in the proposed configuration. Some adjustments were made to the operation values with respect to the previous results, in order to favor flowability inside the extruder. Thus, the SS was $150 \mathrm{rpm}$ in trials \#8 and 9, and $250 \mathrm{rpm}$ in trial \#10. Moreover, the L/S ratio was kept at the intermediate value of 1.2, except for trial \#8, where it was 0.7 to be able to reach a stable production.

As can be seen in Figure 2, in these experiments (\#8, 9 and 10) the glucose release leveled up with the increase of the $\mathrm{NaOH} / \mathrm{DM}$ ratio and so the GR value at $20 \%$ was statistically significant. Although it appeared to be a certain decrease of the $\mathrm{XR}$ as the amount of catalyst increased, the differences turned out to be non-significant. The best results were then $12 \mathrm{~g}$ of glucose and $5.8 \mathrm{~g}$ xylose $/ 100 \mathrm{~g}$ extrudate, which means $24.5 \%$ of glucan conversion and $56.5 \%$ of xylan conversion. In which concerns the extrudate composition presented in Table 2, cellulose is not affected by the amount of alkali; however, there are significant differences between the hemicellulose and lignin composition at $5 \%$ and $10 \%$ or $20 \% \mathrm{NaOH} / \mathrm{DM}$. This is confirmed by a higher solubilization of xylose in the filtrate (see Table 3). Deacetylation is also higher at high $\mathrm{NaOH} / \mathrm{DM}$ ratios. As expected, the values shown in Table 2 for the amount of ash increase as the amount of alkali added increases, due to the greater amount of $\mathrm{H}_{2} \mathrm{SO}_{4}$ needed to neutralize the mixture and the subsequently formation of salts. The greater flow of acid added also influences the efficiency of the filtrate reported in Table 3.

Sodium hydroxide is responsible for the cleavage of the ether and ester bonds between lignin and hemicellulose and also affects the ether and carbon to carbon bonds intra-lignin, resulting in deacetylation and delignification of the biomass and solubilization of hemicelluloses [34]. The results from the present work support the deacetylation phenomena that occurred during alkaline extrusion, based on significant acetic acid recovery yields in the filtrates and washing liquid shown in Table 3. However, no furfural neither HMF were found and monomeric phenols such as vainillin or syringaldehyde were neither detected (data not shown). The presence of acetic acid in the filtrate implies that the extrudates, which in this strategy are not washed out of the extruder, also contain certain amounts of this compound that may affect enzymes performance [35], but the dilution up to the desired consistency (in this work, $5 \%(w / w)$ ) makes the acetic acid concentration to decrease, so alleviating the potential inhibition effect. 
Other authors have reported deacetylation and / or delignification in alkaline extrusion of different biomasses. For example, Choi et al. [33] extruded empty fruit bunches at high temperature $\left(170{ }^{\circ} \mathrm{C}\right)$ and low screw speed ( $5 \mathrm{rpm})$ and found that, as the amount of catalyst increased from $5 \%$ to $20 \% \mathrm{NaOH} / \mathrm{DM}$, the glucan content in the extrudate increases, corresponding to a decrease of the hemicellulosic sugars and lignin due to solubilization. Similar behavior was reported by Han et al. [35] and Duque et al. [27] on alkali-extruded barley straw. Xylan solubilization related to the increase of $\mathrm{NaOH}$ was also reported by Liu et al. [36] and Um et al. [37] working with corn stover and rape straw, respectively. Nevertheless, delignification due to alkaline extrusion did not always occurred, as noted by Liu et al. [36], Duque et al. [18] and Kang et al. [38] on different herbaceous biomasses.

To sum up the results from this part of the work with eucalyptus, extrusion with filtration was successfully carried out and some favorable operation conditions have been identified: Lowest possible $\mathrm{SS}$, high $\mathrm{L} / \mathrm{S}$ ratios $(>1)$ and moderate to high $\mathrm{NaOH} / \mathrm{DM}$ ratios $(\geq 8 \%)$. The effect of increasing the temperature over $100{ }^{\circ} \mathrm{C}$ was not possible to investigate in the present configuration, therefore, a new concept was tested, aiming at achieving good flowability at high temperature.

\subsection{Alkaline Extrusion without Filtration}

\subsubsection{Modification of the Screw Configuration}

As can be seen in Figure 3, for the purpose of testing high temperatures, the problematic zone (i.e., filtration) was removed from the process configuration. Two reverse flow mixing screws were placed in barrel \#3 and at the end of barrel \#5 to delimit the high temperature zone by the formation of dynamic plugs. Other mixing screws along the profile helped the mixture of the biomass with the alkaline and acid solutions. A profile temperature was set with increasing values, reaching its highest point in barrels \#4 and 5 .

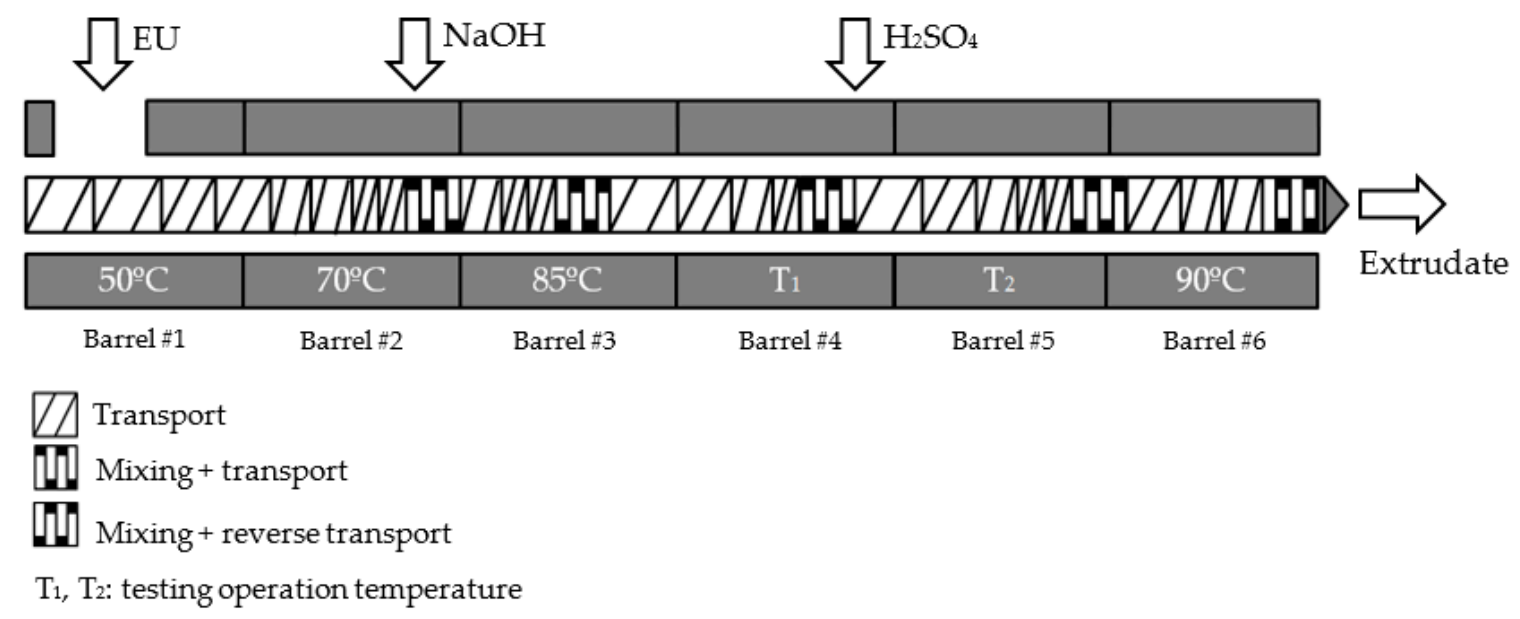

Figure 3. Barrel and screw configuration for the alkaline extrusion of eucalyptus with neutralization in a twin-screw extruder. Without filtration.

With the removal of the filter, only one material output is left. The resulting pretreated material will be called hereafter complete extrudate. With this configuration, temperatures of 125 and $150{ }^{\circ} \mathrm{C}$ could be attained (Table 1, experiments 11 and 12).

\subsubsection{Performance of Complete Extrudates}

No significant differences were found between the compositions of the two complete extrudates (see Table 2, rows 11 and 12), but in comparison to the previous experiments, some aspects differed. The absence of filtration had a clear consequence in the form of increase of the amount of ash up to almost $15 \%$ of the weight of extrudate. This also affected the concentration of cellulose and lignin, which decreased by $10 \%$ and $6 \%$, compared, for example, to experiment \#4. 
In spite of being associated to a SME comparable to those of the experiments with filtration $\left(114 \mathrm{Wh} \mathrm{kg}^{-1}\right.$ ), the sugar release of the complete extrudate at $125^{\circ} \mathrm{C}$ (see Figure 2, column 11) was very low, particularly in the case of glucose: GR was only $6.8 \mathrm{~g} / 100 \mathrm{~g}$ extrudate (equivalent to $15 \%$ of glucan conversion), whereas XR was $5.7 \mathrm{~g} / 100 \mathrm{~g}$ dry extrudate, more in the line of previous trials. This indicates that there is a mechanical effect associated to the filtration step that is necessary to obtain a good pretreatment of eucalyptus. Moreover, this mechanical effect seems to be more important for cellulose, since in its absence, the glucose release drops to levels even below to the ones of the control extrudate with water and filtration. The xyloserelease, nevertheless, seems to be more affected by the chemical action of $\mathrm{NaOH}$, as it reaches similar values for all the trials with chemical catalysts.

At $150{ }^{\circ} \mathrm{C}$ (experiment \#12), a much higher torque than in trial \#11 is developed, greater than any of the $\mathrm{NaOH}$-extrusion with filtration trials (experiment 1 to 10). This resulted in a significant increase of the glucose and xylose release, which reached 16 and $8.4 \mathrm{~g} / 100 \mathrm{~g}$ extrudate, respectively, corresponding to $37.6 \%$ and $74.6 \%$ of glucan and xylan conversion. This means that the GR of the extrusion at $150{ }^{\circ} \mathrm{C}$ (trial \#12) more than doubled the one of the experiment at $125^{\circ} \mathrm{C}$ (trial \#11).

The enzymatic digestibility of complete extrudates was not as good as expected, especially in the case of $125^{\circ} \mathrm{C}$ (trial \#11). The high amount of ash in the extrudates produced in this configuration may be hindering the performance of enzymes. It has been demonstrated that the washing of the extrudates removes chemical residues and enzyme inhibitors and is beneficial for the enzymatic hydrolysis step $[25,39]$. Therefore, the complete extrudates were washed with ten times the weight of distillate water and the resulting cake was submitted to $\mathrm{EH}$ as usual.

\subsubsection{Performance of Washed Extrudates}

The washing of the extrudates removed most of the inorganic salts formed during the neutralization step, as can be seen by the content of ash measured in extrudates 13 and 14 shown in Table 2. This resulted in a concentration of cellulose and lignin, mainly. Comparing both washed extrudates, there seem to be a small loss of hemicellulosic sugars at $150{ }^{\circ} \mathrm{C}$ (trial \#14) compared to $125^{\circ} \mathrm{C}$ (trial \#13). In fact, as can be seen in Table 3 (rows 13 and 14), almost all glucose remained in the extrudate after washing, however, there was some xylose solubilized in the liquid (more in trial \#14), which could account for the difference in the hemicellulose content between both extrudates. The deacetylation effect of the pretreatment at 125 and $150{ }^{\circ} \mathrm{C}$ was in the line of the results from previous experiments with filtration.

Thanks to the washing, the glucose release by EH was increased 1.2-fold for both extrudates, attaining $19.4 \mathrm{~g} / 100 \mathrm{~g}$ extrudate in trial \#14 and $8.3 \mathrm{~g} / 100 \mathrm{~g}$ extrudate in the case of experiment \#13 (see Figure 2), which, in terms of GC, would be $35.8 \%$ and $15 \%$, respectively. Nevertheless, the washing had no noticeable effect on the xylose release.

Results show that washing improved the glucose release compared to complete extrudates, and also a positive effect of increasing extrusion temperature from 125 to $150{ }^{\circ} \mathrm{C}$. However, when talking about the glucan and xylan conversion, the yield is slightly lower in the case of the washed extrudates with respect to the complete ones and no clear effect of washing in the enzymatic digestibility of the substrates can be concluded. Thus, the increase in the sugar release found in washed substrates can be mostly attributed to the concentration of cellulose in the washing step.

\section{Conclusions}

Eucalyptus wood valorization through an extrusion pretreatment requires a careful planning of the configuration and setting of the operation conditions. In the present work, low screw speed, high $\mathrm{L} / \mathrm{S}$ ratio inside the extruder, $\mathrm{NaOH} / \mathrm{DM}$ concentrations $\geq 8 \%$ and high temperature $\left(>100{ }^{\circ} \mathrm{C}\right)$ have been demonstrated to favor the glucose and xylose release by $\mathrm{EH}$ of the resulting substrates from the alkaline extrusion with neutralization and filtration inside the extruder.

The best results were obtained in the configuration without filtration at $150^{\circ} \mathrm{C}$ and with a posterior washing of the extrudate obtained. In spite of this, the improvement in the glucose release does not 
lead to an equal rise of the glucan conversion. Therefore, the convenience of the washing step must be addressed in an overall assessment of the downstream processing operations on the pretreatment, since the benefits are not so clear and this adds complexity and cost to the process.

Filtration, however, has been proved to have a beneficial effect not only by the removal of inorganic salts from the extrudate, but also at a mechanical pretreatment level. Taking this into account, the ideal extrusion pretreatment process for eucalyptus biomass would comprehend a configuration with filtration and temperature around $150{ }^{\circ} \mathrm{C}$. Such a process cannot be developed in the extrusion pilot plant used in this work, but could be investigated in a bigger facility.

Author Contributions: Conceptualization, A.D. and P.M.; methodology, A.D.; investigation, A.D.; analytical tools, A.G.; formal analysis, A.D. and A.G.; writing—original draft preparation, A.D.; writing-review and editing, P.M. and A.D.; supervision, P.M. and M.B.; project administration, P.M. and M.B.

Funding: This research was funded by the European Commission in the frame of the BABET-REAL5 project (Horizon 2020 Program, Project No. 654365).

Acknowledgments: The authors want to thank the INIA (Uruguay) for providing the eucalyptus biomass to complete this work.

Conflicts of Interest: The authors declare no conflict of interest. The funders had no role in the design of the study; in the collection, analyses, or interpretation of data; in the writing of the manuscript, or in the decision to publish the results.

\section{References}

1. REN21. Renewables 2018 Global Status Report; REN21 Secretariat: Paris, France, 2018.

2. Shepherd, M.; Bartke, J.; Lee, D.J.; Brawner, J.; Bush, D.; Turnbull, P.; Macdonel, P.; Brown, T.R.; Simmons, B.; Henry, R. Eucalyptus as biofuel feedstock. Biofuels 2011, 2, 639-657. [CrossRef]

3. Taherzadeh, M.J.; Karimi, K. Pretreatment of lignocellulosic wastes to improve ethanol and biogas production: A review. Int. J. Mol. Sci. 2008, 9, 1621-1651. [CrossRef] [PubMed]

4. Bajpai, P. Structure of Lignocellulose. In Pretreatment of Lignocellulosic Biomass for Biofuel Production; Springer: Singapore, 2016.

5. Volynets, B.; Ein-Mozaffari, F.; Dahman, Y. Biomass processing into ethanol: Pretreatment, enzymatic hydrolysis, fermentation, rheology, and mixing. Green Process. Synth. 2017, 6, 1-22. [CrossRef]

6. Alvira, P.; Tomas-Pejó, E.; Ballesteros, M.; Negro, M.J. Pretreatment technologies for an efficient bioethanol production process based on enzymatic hydrolysis: A review. Bioresour. Technol. 2010, 101, 4851-4861. [CrossRef] [PubMed]

7. Duque, A.; Manzanares, P.; Ballesteros, M. Extrusion as a pretreatment for lignocellulosic biomass: Fundamentals and applications. Renew. Energy 2017, 114, 1427-1441. [CrossRef]

8. Romaní, A.; Garrote, G.; Parajó, J.C. Bioethanol production from autohydrolyzed Eucalyptus globulus by Simultaneous Saccharification and Fermentation operating at high solids loading. Fuel 2012, 94, 305-312. [CrossRef]

9. McIntosh, S.; Vancov, T.; PAlmer, J.; Spain, M. Ethanol production from Eucalyptus plantation thinnings. Bioresour. Technol. 2012, 110, 264-272. [CrossRef] [PubMed]

10. Lima, M.A.; Lavorente, G.B.; da Silva, H.K.P. Effects of pretreatment on morphology, chemical composition and enzymatic digestibility of eucalyptus bark: A potentially valuable source of fermentable sugars for biofuel production-Part 1. Biotechnol. Biofuels 2013, 6, 75. [CrossRef] [PubMed]

11. Karunanithy, C.; Muthukumarappan, K.; Gibbons, W.R. Extrusion pretreatment of pine wood chips. Appl. Biochem. Biotechnol. 2012, 167, 81-99. [CrossRef] [PubMed]

12. Lee, S.H.; Teramoto, Y.; Endo, T. Enhancement of enzymatic accessibility by fibrillation of woody biomass using batch-type kneader with twin-screw elements. Bioresour. Technol. 2010, 101, 769-774. [CrossRef] [PubMed]

13. Lee, S.-H.; Teramoto, Y.; Endo, T. Enzymatic saccharification of woody biomass micro/nanofibrillated by continuous extrusion process I-Effect of additives with cellulose affinity. Bioresour. Technol. 2009, 100, 275-279. [CrossRef] [PubMed] 
14. Lee, S.H.; Inoue, S.; Teramoto, Y.; Endo, T. Enzymatic saccharification of woody biomass micro/nanofibrillated by continuous extrusion process II: Effect of hot-compressed water treatment. Bioresour. Technol. 2010, 101, 9645-9649. [CrossRef] [PubMed]

15. Kim, T.H.; Choi, C.H.; Keun, K. Bioconversion of sawdust into ethanol using dilute sulfuric acid-assisted continuous twin screw-driven reactor pretreatment and fed-batch simultaneous saccharification and fermentation. Bioresour. Technol. 2013, 130, 306-313. [CrossRef] [PubMed]

16. Senturk, S.; Gevgilili, H.; Kaylon, D.M. Biomass pretreatment strategies via control of rheoroligal behavior of biomass suspensions and reactive twin screw extrusion processing. Bioresour. Technol. 2011, 102, 9068-9075. [CrossRef] [PubMed]

17. Brault, J. Développement d'un Procédé Innovant de Dégradation Enzymatique des Parois Végétales Pour la Production de Bioéthanol Seconde Génération. Ph.D. Thesis, INPT Toulouse, Toulouse, France, 2013.

18. Duque, A.; Manzanares, P.; Ballesteros, I.; Negro, M.J.; Oliva, J.M.; Saez, F.; Ballesteros, M. Study of process configuration and catalyst concentration in integrated alkaline extrusion of barley straw for bioethanol production. Fuel 2014, 134, 448-454. [CrossRef]

19. National Renewable Energy Laboratory (NREL). Chemical Analysis and Testing Laboratory Analytical Procedures; NREL: Golden, CO, USA, 2007.

20. Choi, C.H.; Oh, K.K. Application of a continuous twin screw-driven process for dilute acid pretreatment of rape straw. Bioresour. Technol. 2012, 110, 349-354. [CrossRef] [PubMed]

21. Kuster Moro, M.; Sposina, R.; Sant'Ana da Silva, A.; Fujimoto, M.D.; Melo, P.A.; Secchi, A.R.; da Silva Bon, E.P. Continuous pretreatment of sugarcane biomass using a twin-screw extruder. Ind. Crop. Prod. 2017, 97 (Suppl. C), 509-517. [CrossRef]

22. Zheng, J.; Choo, K.; Rehmann, L. Xylose removal from lignocellulosic biomass via a twin-screw extruder: The effects of screw configurations and operating conditions. Biomass Bioenergy 2016, 88, 10-16. [CrossRef]

23. Vandenbossche, V.; Brault, J.; Vilarem, G.; Rigal, L. Bio-catalytic action of twin-screw extruder enzymatic hydrolysis onthe deconstruction of annual plant material: Case of sweet cornco-products. Ind. Crop. Prod. 2015, 67, 239-248. [CrossRef]

24. Yoo, J.; Alavi, S.; Vadlani, P.; Behnke, K.C. Soybean hulls pretreated using thermo-mechanical extrusion-Hydrolysis efficiency, fermentation inhibitors, and ethanol yield. Appl. Biochem. Biotechnol. 2012, 166, 576-589. [CrossRef] [PubMed]

25. Lamsal, B.; Yoo, J.; Brijwani, K.; Alavi, S. Extrusion as a thermo-mechanical pre-treatment for lignocellulosic ethanol. Biomass Bioenergy 2010, 34, 1703-1710. [CrossRef]

26. Scott, C.T.; Samaniuk, J.R.; Klingenberg, D.J. Rheology and extrusion of high-solids biomass. Tappi J. 2011, $10,47-53$.

27. Duque, A.; Manzanares, P.; Ballesteros, I. Optimization of integrated alkaline-extrusion pretreatment of barley straw for sugar production by enzymatic hydrolysis. Process Biochem. 2013, 48, 775-781. [CrossRef]

28. Zhang, S.; Xu, Y.; Hanna, M. Pretreatment of Corn Stover with Twin-Screw Extrusion Followed by Enzymatic Saccharification. Appl. Biochem. Biotechnol. 2012, 166, 458-469. [CrossRef] [PubMed]

29. Karunanithy, C.; Muthukumarappan, K. Effect of Extruder Parameters and Moisture Content of Switchgrass, Prairie Cord Grass on Sugar Recovery from Enzymatic Hydrolysis. Appl. Biochem. Biotechnol. 2010, 162, 1785-1803. [CrossRef] [PubMed]

30. Negro, M.J.; Duque, A.; Manzanares, P.; Sáez, F.; Oliva, J.M.; Ballesteros, I.; Ballesteros, M. Alkaline twin-screw extrusion fractionation of olive-treepruning biomass. Ind. Crop. Prod. 2015, 74, 336-341. [CrossRef]

31. Karunanithy, C.; Muthukumarappan, K. A comparative study on torque requirement during extrusion pretreatment of different feedstocks. Bioenergy Res. 2012, 5, 263-276. [CrossRef]

32. Da Silva, A.; Sposina, R.; Endo, T.; Bon, E.P.; Lee, S.H. Continuous pretreatment of sugarcane bagasse at high loading in an ionic liquid using a twin-screw extruder. Green Chem. 2013, 15, 1991-2001. [CrossRef]

33. Choi, W.I.; Oh, K.K.; Park, J.Y.; Lee, J.S. Continuous sodium hydroxide-catalyzed pretreatment of empty fruit bunches (EFB) by continuous twin-screw-driven reactor (CTSR). J. Chem. Technol. Biotechnol. 2014, 89, 290-296. [CrossRef]

34. Kim, J.S.; Lee, Y.Y.; Kim, T.H. A review on alkaline pretreatment technology for bioconversion of lignocellulosic biomass. Bioresour. Technol. 2016, 199, 42-48. [CrossRef] [PubMed] 
35. Van Walsum, G.P.; Um, B.H. Effect of pretreatment severity on accumulation of major degradation products from dilute acid pretreated corn stover and subsequent inhibition of enzymatic hydrolysis of cellulose. Appl. Biochem. Biotechnol. 2012, 168, 406-420.

36. Han, M.; Kang, K.E.; Kim, Y.; Choi, G.W. High efficiency bioethanol production from barley straw using a continuous pretreatment reactor. Process Biochem. 2013, 48, 488-495. [CrossRef]

37. Liu, C.; van der Heide, E.; Wang, H.; Li, B.; Yu, G.; Mu, X. Alkaline twin-screw extrusion pretreatment for fermentable sugar production. Biotechnol. Biofuels 2013, 6, 97. [CrossRef] [PubMed]

38. Um, B.-H.; Choi, C.H.; Oh, K.K. Chemicals effect on the enzymatic digestibility of rape straw over the thermo-mechanical pretreatment using a continuous twin screw-driven reactor (CTSR). Bioresour. Technol. 2013, 130, 38-44. [CrossRef] [PubMed]

39. Kang, K.E.; Han, M.; Moon, S.K.; Kang, H.W.; Kim, Y.; Cha, Y.L.; Choi, G.W. Optimization of alkali-extrusion pretreatment with twin-screw for bioethanol production from Mischantus. Fuel 2013, 109, 520-526. [CrossRef]

(C) 2018 by the authors. Licensee MDPI, Basel, Switzerland. This article is an open access article distributed under the terms and conditions of the Creative Commons Attribution (CC BY) license (http://creativecommons.org/licenses/by/4.0/). 